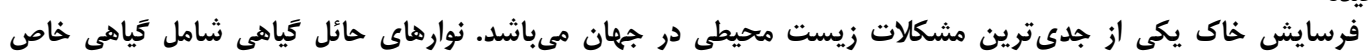

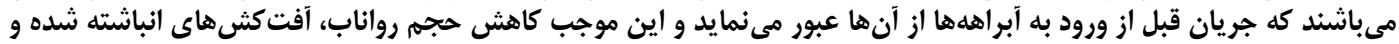

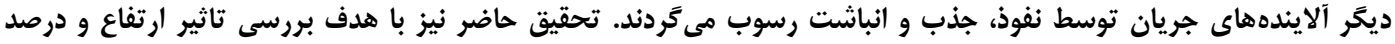

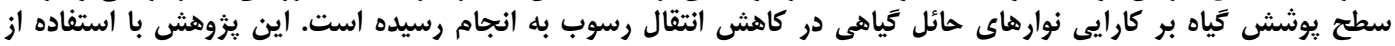

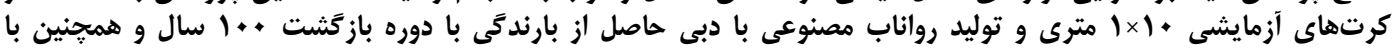

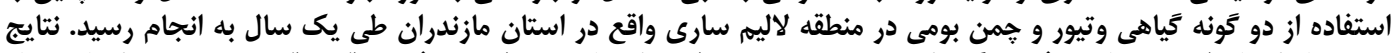

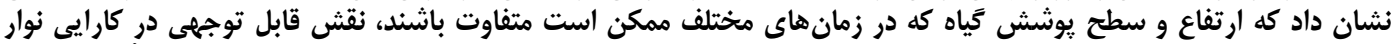

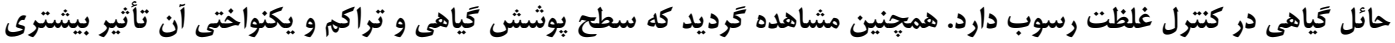

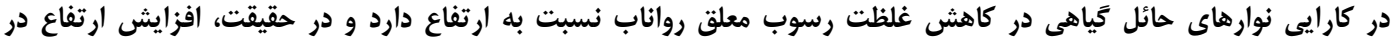

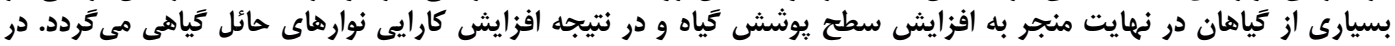

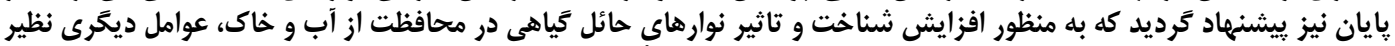

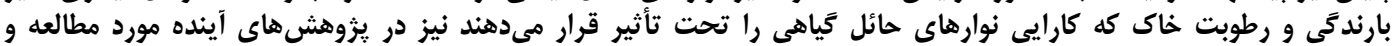

بر رسى قرار تيرند.

وازههاى كليدى: رواناب مصنوعى، غلظت رسوب، فرسايش خاك، لاليم، نوارهاى حائل كَياهى

قآوردن زيستخاه و شرايط مناسب براى آبزيان موران مورد استفاده

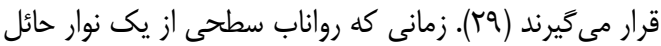

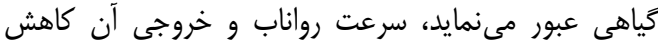

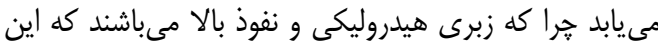

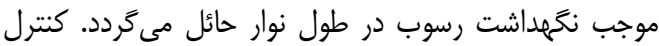

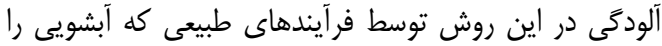

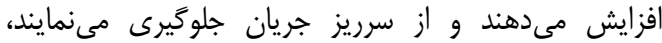

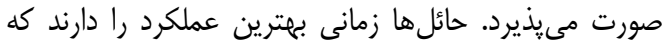

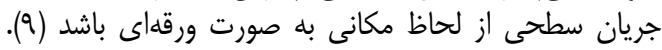

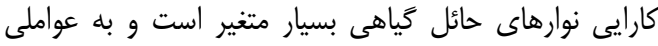

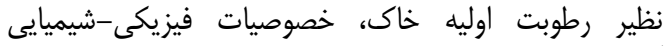

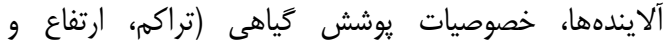

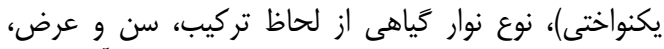

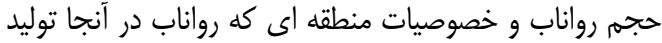

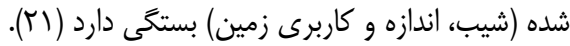

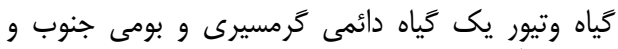

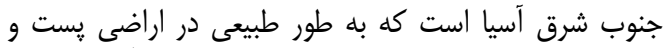

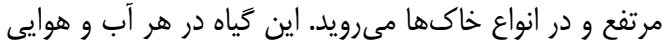

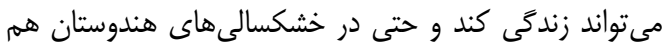

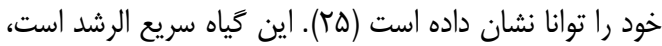

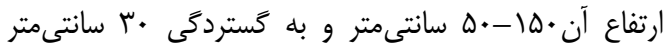

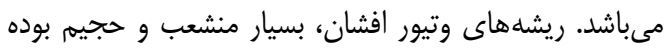

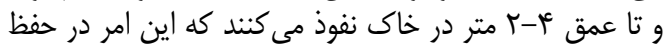

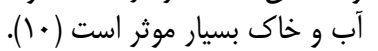

در كذشته يزوهشيار موثاى بسيارى در زمينه تاثير نوارهاى

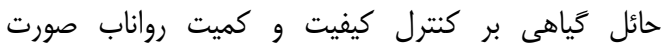

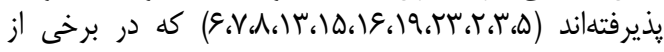

مقدمه

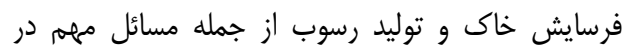

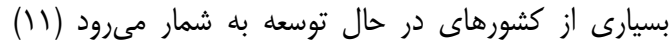

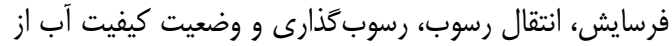

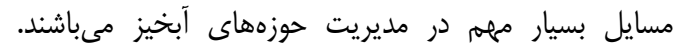

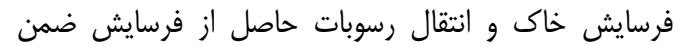

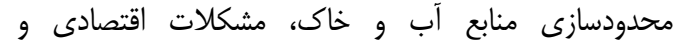

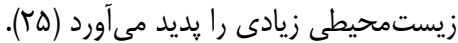

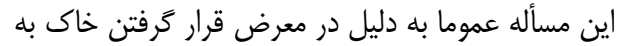

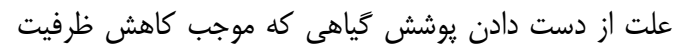

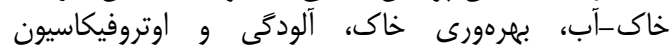

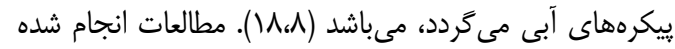

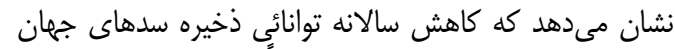

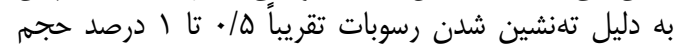

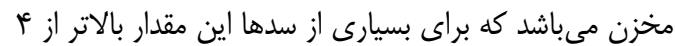

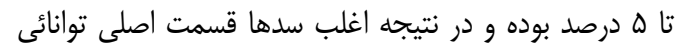

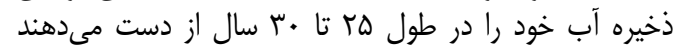
(TV)

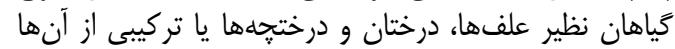

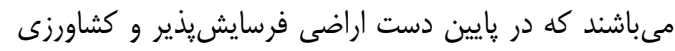

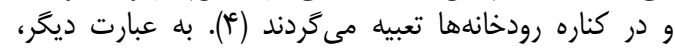

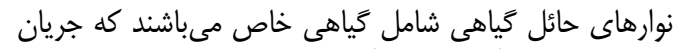

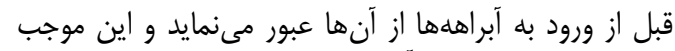

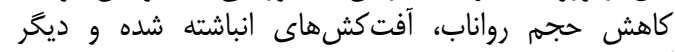

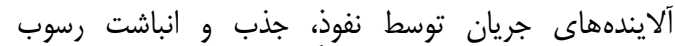

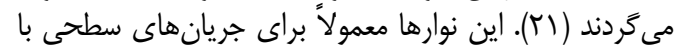
شدت كم، تلهاندازى رسوب، فيلتر كردن مواد مغذى و و فران مانه 
نوار حائل گياهى را اصلاح نموده و بهبود بخشيده است.

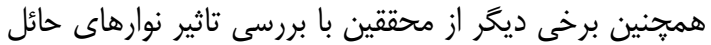

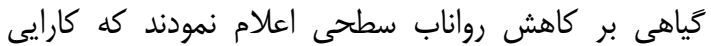

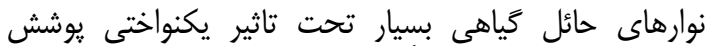

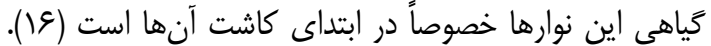

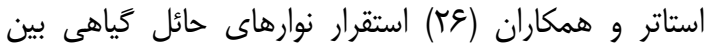

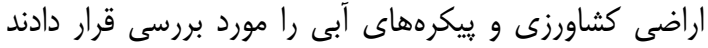

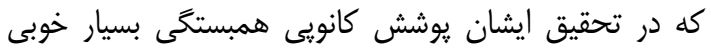

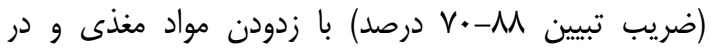

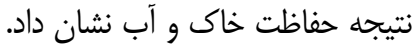

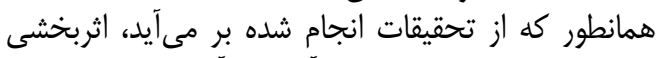

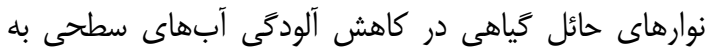

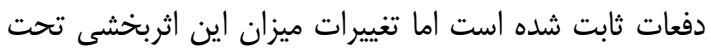

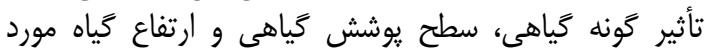

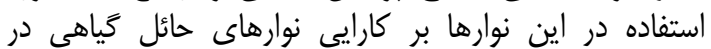

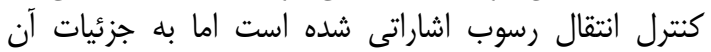

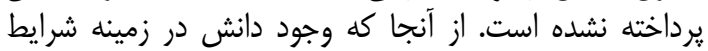

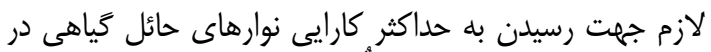

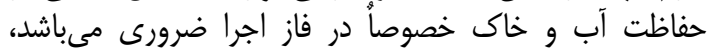

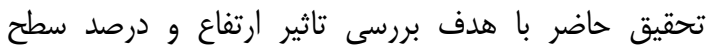

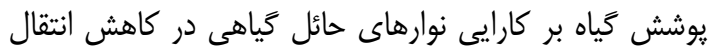
رسوب به انجام رسيده است.

\section{مواد و روشها منطقه مورد مطالعه}

عرصه اين تحقيق بخشى از اراضى كشاورزى ديم منطقة

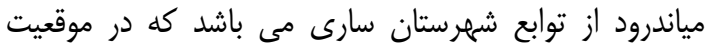

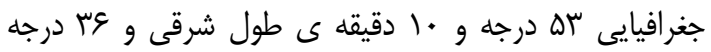

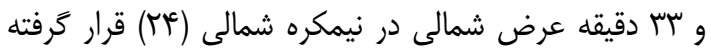

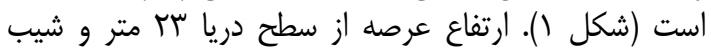

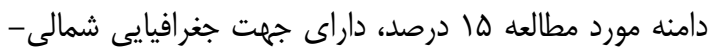

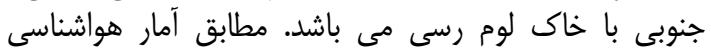

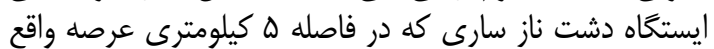

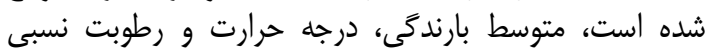

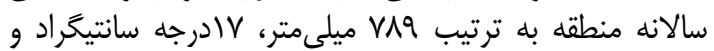
\% مى باشد. VV

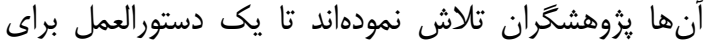

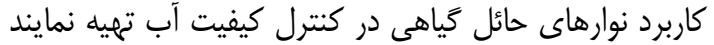

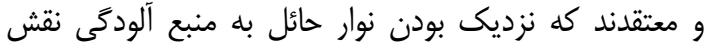

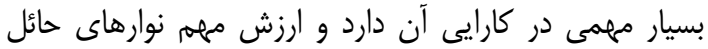

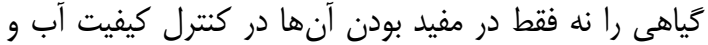

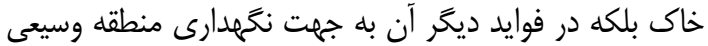

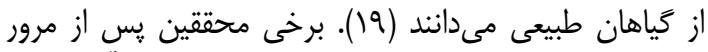

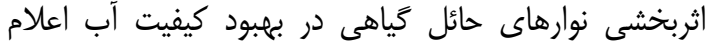

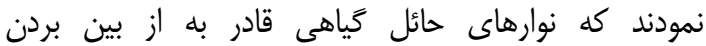

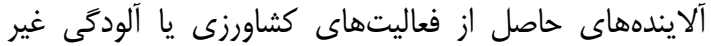

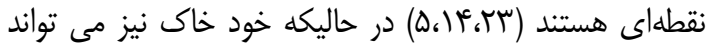

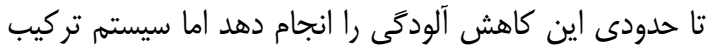

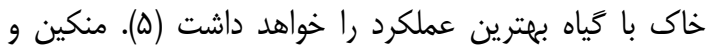

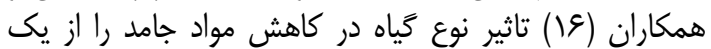

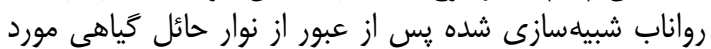

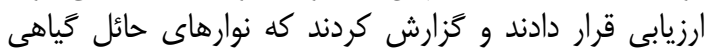

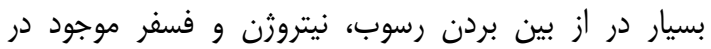

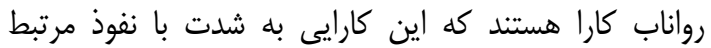

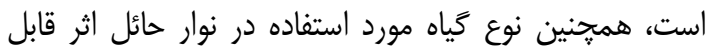

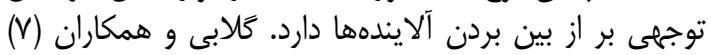

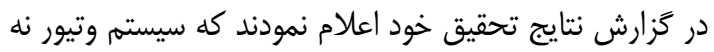

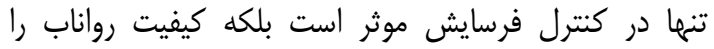

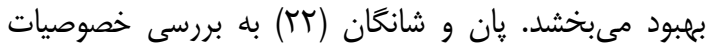

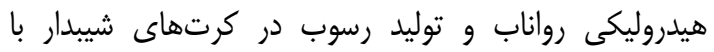

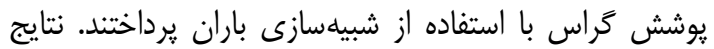

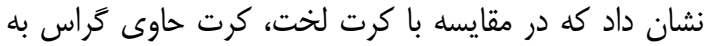

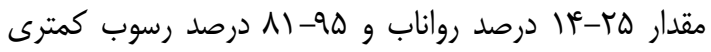

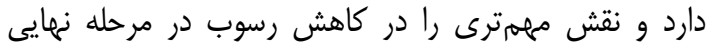

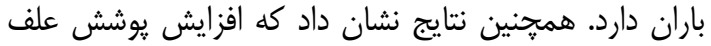

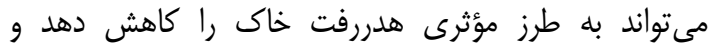

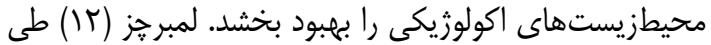

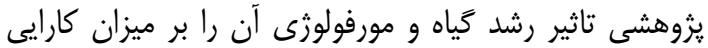

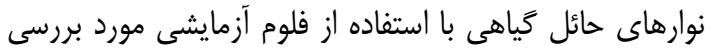

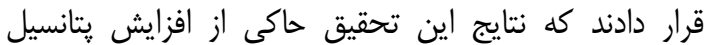

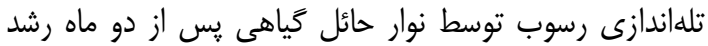

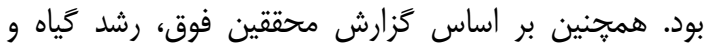

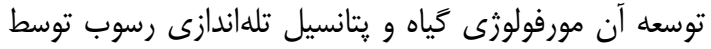




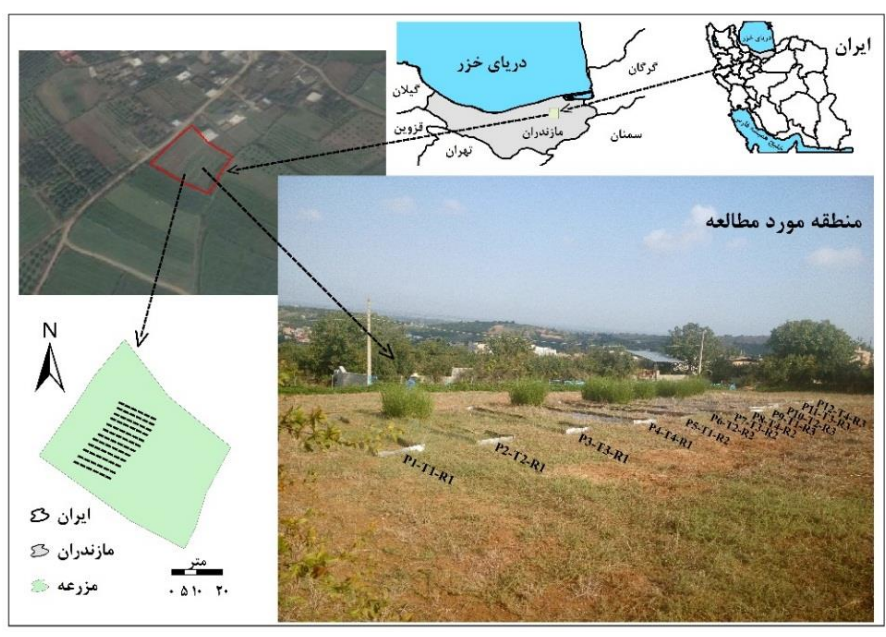

شكل 1- موقعيت جغرافيايى منطقه مورد مطالعه

Figure 1. Location of the study area

تيمار ا: وتيور كراس ،تيمار ז: جمن بومى، تيمار ץ: شاهد (بدون يوشش)

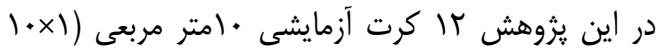

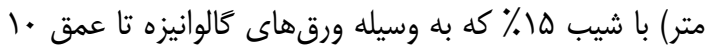

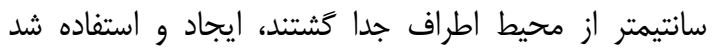

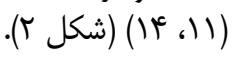

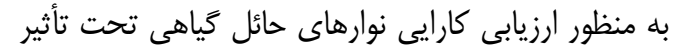

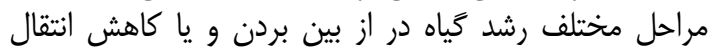

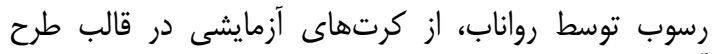

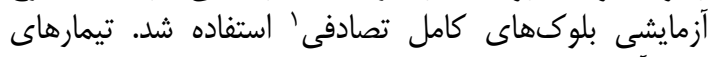
مورد آزمايش در اين تحقيق به شرح زير مىباشندا: الصناده تئل

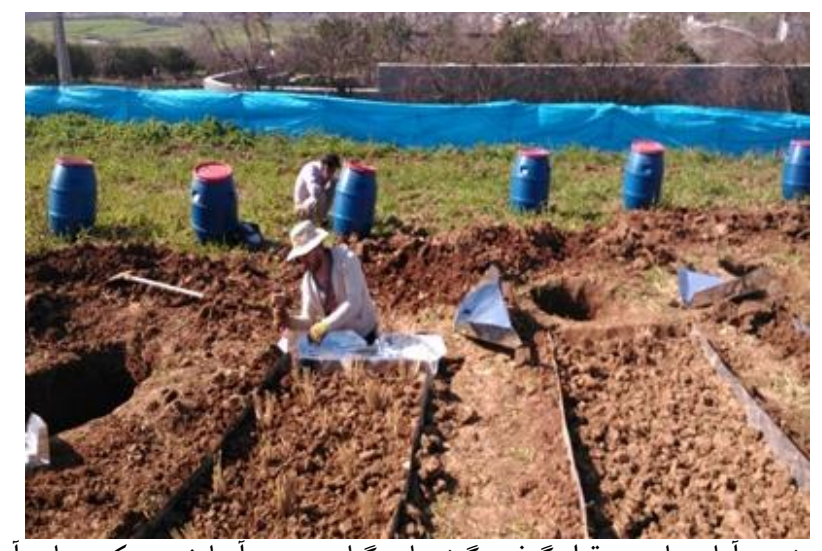

شكل r- نحوه أمادهازى و قرار گرفتن گونههاى گياهى مورد أزمايش در كرتهاى آزمايشى

Figure 2. Preparation and installation of the studied plant species in the plots

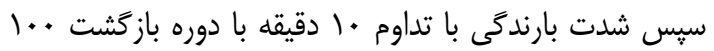
سال از مدل قهرمان و آبخضر برآورد و استخراج كرديد داريد بله منظور تعيين ميزان دبى رواني اناب مصنوعى، ابتدا دادهها

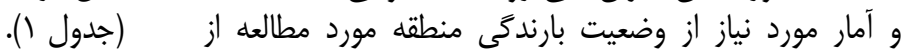

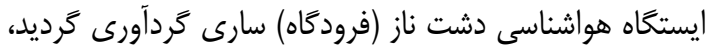

جدول ا- نتايج حاصل از محاسبه مقادير شدت بارش (mm/h) در دوره بازگشتهاى مختلف براى منطقه مورد مطالعه Table 1. The results of rainfall intensity calculation for various return periods in the study area

\begin{tabular}{|c|c|c|c|c|c|c|}
\hline \multicolumn{6}{|c|}{ دوره باز كَشت (سال) } & \multirow{2}{*}{ تداوم بارش (دقيقه) } \\
\hline $1 \cdots$ & a. & $r \Delta$ & 1. & $Q$ & $r$ & \\
\hline$\%$ \%/G & $V T / T^{\sigma}$ & $9 \pi / \Lambda$ & $\Delta F / \Lambda$ & $F V / F^{e}$ & $r r / q$ & 1. \\
\hline
\end{tabular}


19.

نمونلبردارى رواناب

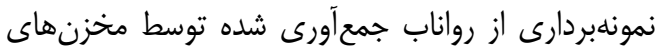

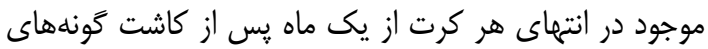

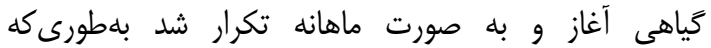

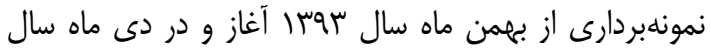

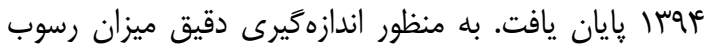

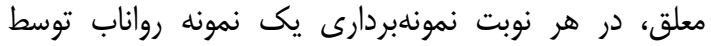

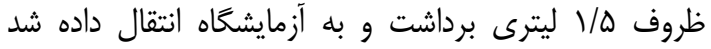

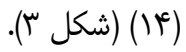

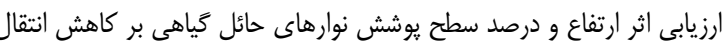

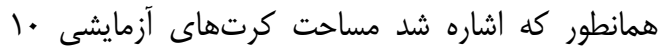

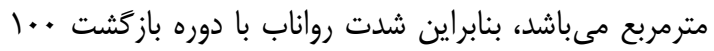

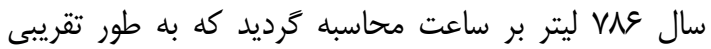

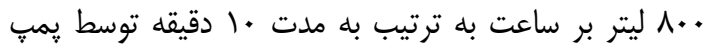

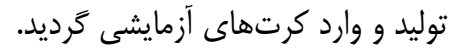

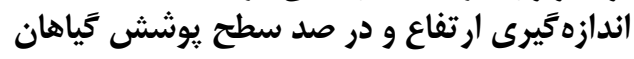

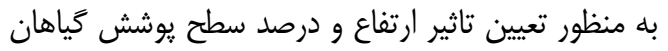

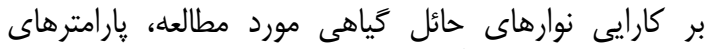

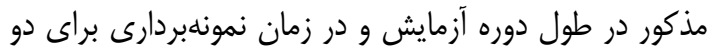

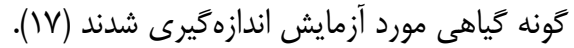

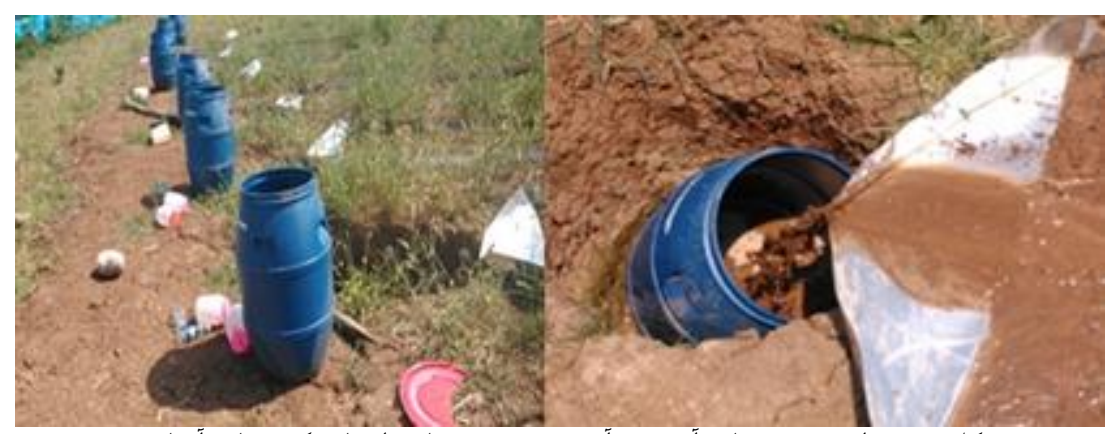

شكل س- برداشت نمونهاى آب جمعاًورى شده در مخازن انتهاى كرتهاى آزمايشى

Figure 3. Water sampling from the collected water in the downslope reservoirs

Effectiveness $\left(T_{i}\right)=\left(1-\frac{P_{i}}{P_{1}}\right) \times 100 \quad(\Gamma)$

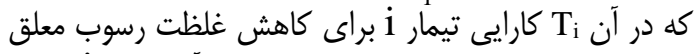

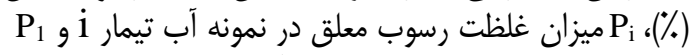
ميزان غلظت رسوب معلق در نمونه آب تيمار شاهد است نيمار آن

\section{نتايج و بحث

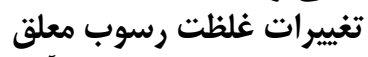

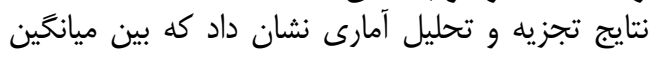

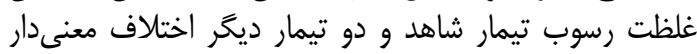

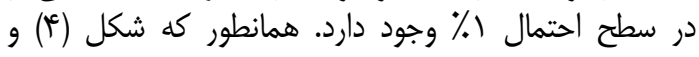

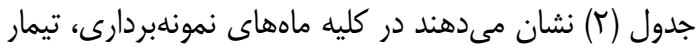

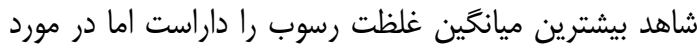

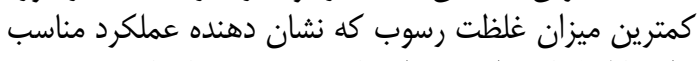

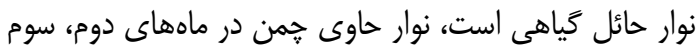

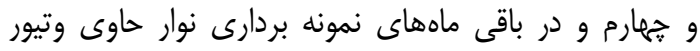

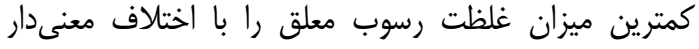
نسبت به ديگر تيمارها نشان دادند.
اندازهيرى غلظت رسوب

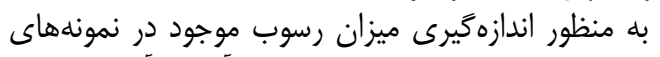

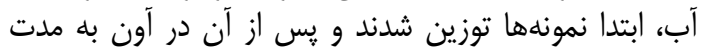

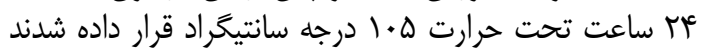

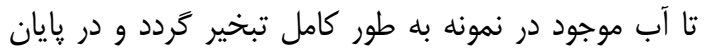

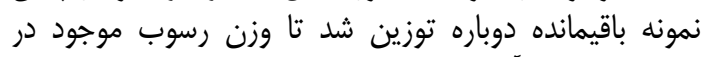

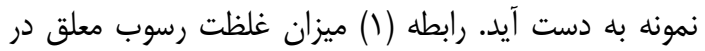

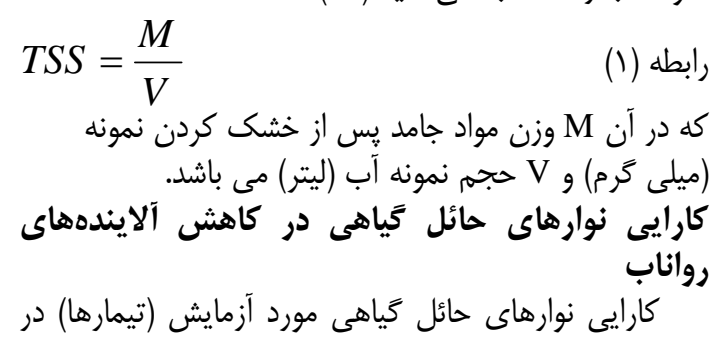

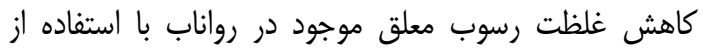
رابطه (Y) محاسبه شد (ז) (I): 


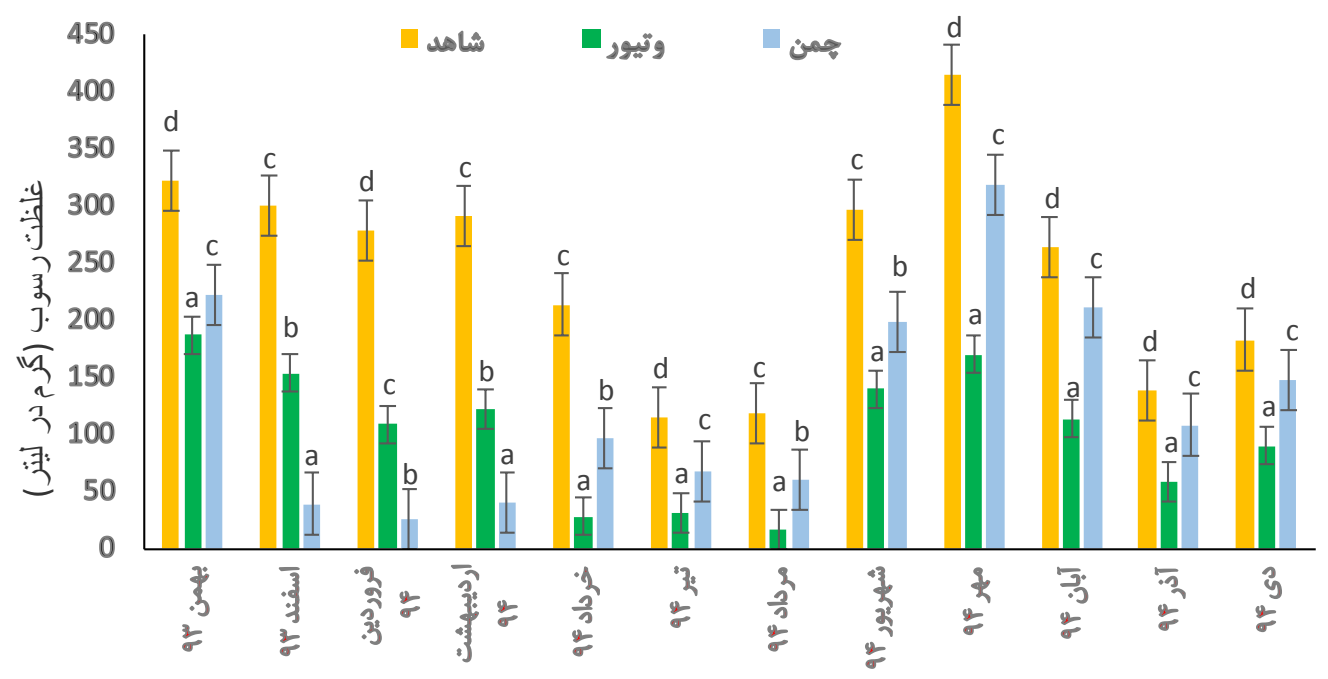

شكل عأ- مقايسه ميانخين غلظت رسوب معلق خروجى از نوارهاى حائل گياهى مورد مطالعه در طول دوره آزمايش

Figure 4. Comparison of outflow sediment concentration means during the study period

جدول r- مقادير ميانخين غلظت رسوب در تيمارهاى مورد بررسى در طول دوره آزمايش Table 2. Means of sediment concentration in the three studied treatments during the study period

\begin{tabular}{|c|c|c|c|c|c|c|c|c|c|c|c|c|}
\hline دى & أذر & آبان & مهر & شهريور & مرداد & تير 9f & خردادثو & ارديبهشت & فروردين & اسفند س9 & بهمن سج & ماه \\
\hline & \multicolumn{11}{|c|}{ غلظت رسوب (ميلى گرم در ليتر) } & تيمار \\
\hline $\mid \wedge r / \& 9$ & ITN/VD & TEM/D. & $r \mid f / \cdot r$ & rqघ/दq & $111 / 49$ & $110 / \%$ & $T / Y / \Delta q$ & $r q . / r V$ & TVV/दg & 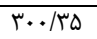 & THT/FD & شاهد \\
\hline$\Lambda 9 / \Delta$. & $\Delta \Lambda / T \Lambda$ & $|1| r / \mu$ & I६q/VD & מא/ק & $\mid \varnothing / \Delta \Lambda$ & $\mathrm{m} / / 1$ & $\mathrm{rV} / \mathrm{VV}$ & $|r| / 9 \mid$ & $1+1 / r q$ & $\mid \Delta \Psi / \Lambda$ & $\mid \Lambda \mathrm{V} / \cdot \mathrm{r}$ & 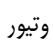 \\
\hline
\end{tabular}

مشاهده مى مردد ارتفاع و سطح يوشش گياهى وتيور در سه

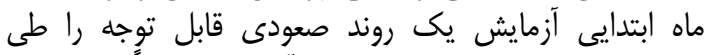

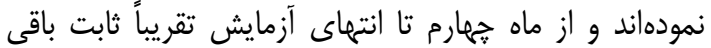

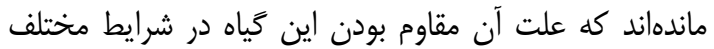

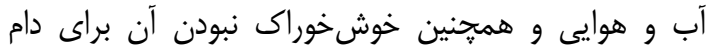

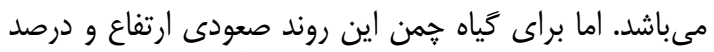

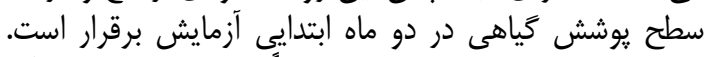

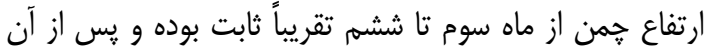

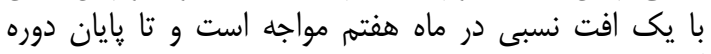

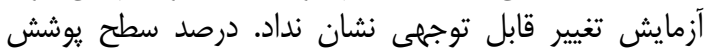

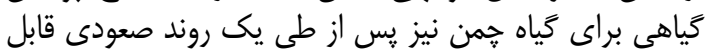

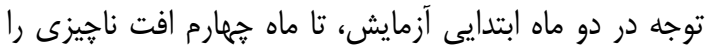

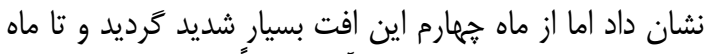

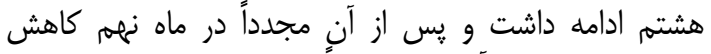

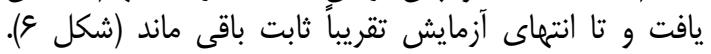

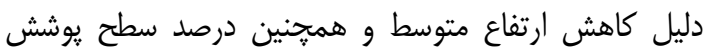

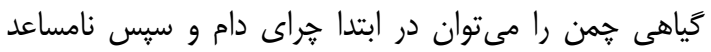
شدن شرايط آب و هوايى براى رئ رشد و بقاى جرى جمن دام دانست.
شكل (أ) و جدول (Y) همجنين نشان مىدهند كه در

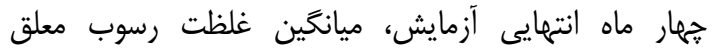

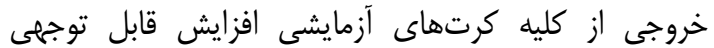

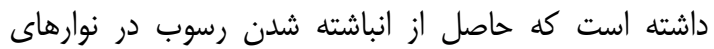

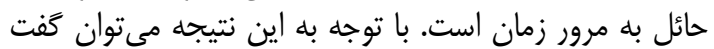

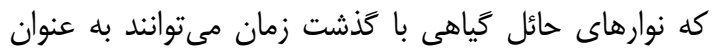

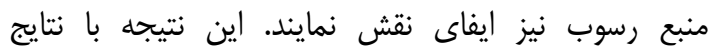

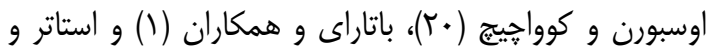

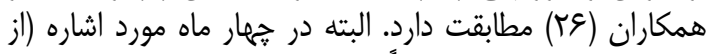

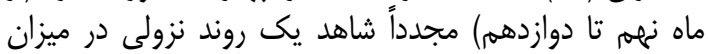

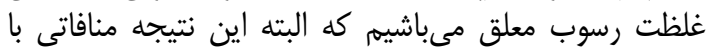

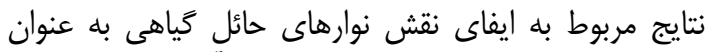

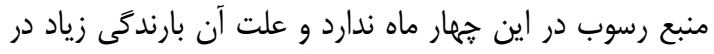

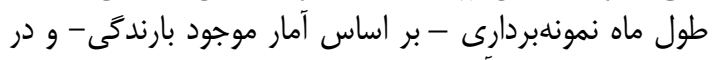

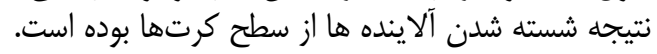

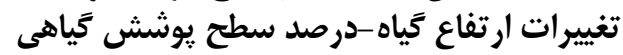

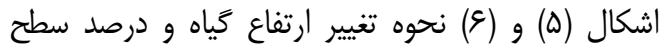

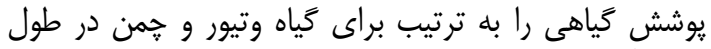

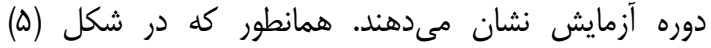




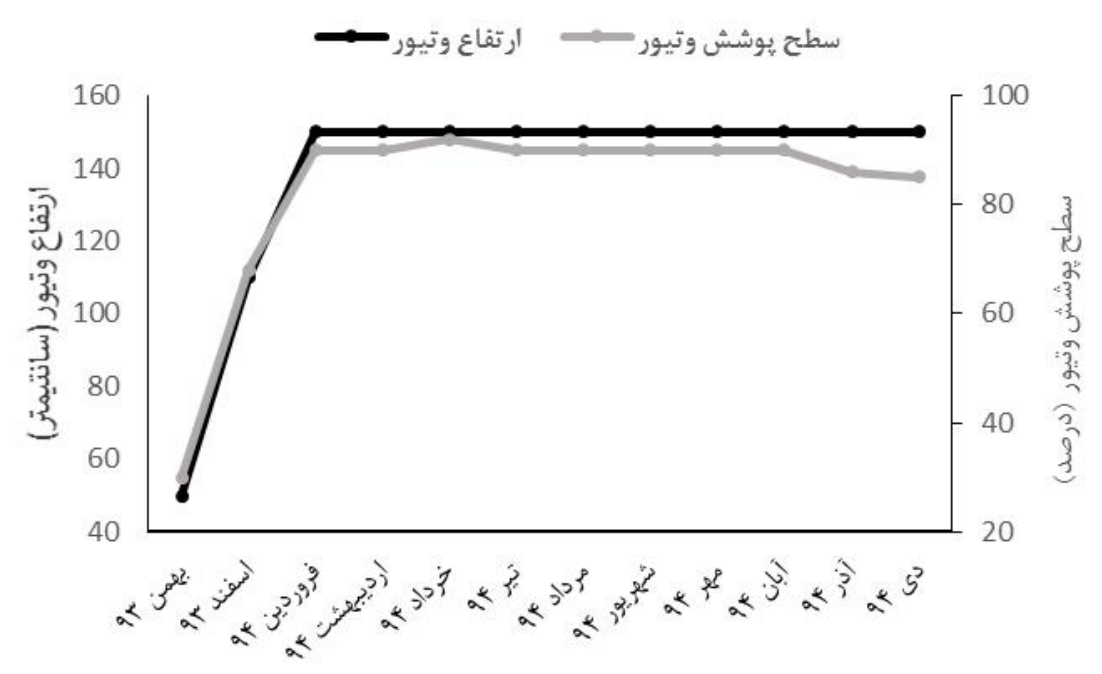

شكل ه- تغييرات ارتفاع و سطح يوشش گياهى وتيور در طول دوره آزمايش

Figure 5. Variations of the vegetation cover and height of vetiver during the study period

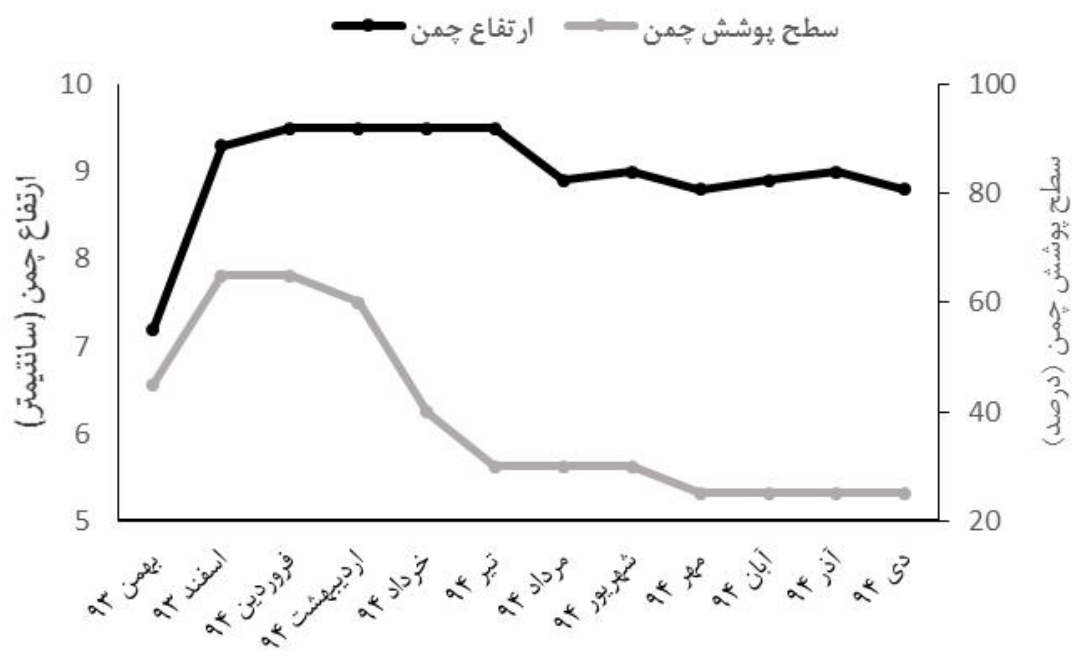

شكل צ- تغييرات ارتفاع و سطح يوشش گياهى جمن در طول دوره آزمايش

Figure 6. Variations of the vegetation cover and height of turf-grass during the study period

شكل (V) تغييرات كارايى نوارهاى حائل كياهى حاوى وتيور و

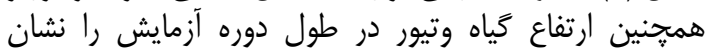

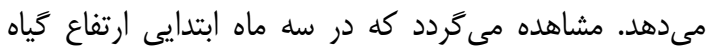

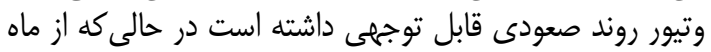
سوم تا انتهاى آزمايش ارتفاع آن ثابت باقى ماند دانده است.
ارتفاع كياه-كارايى نوار حائل تَياهي

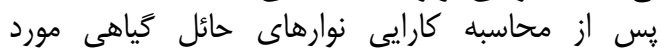

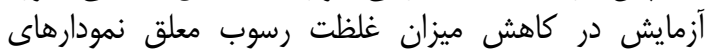

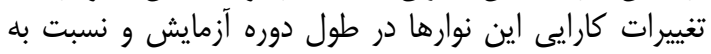

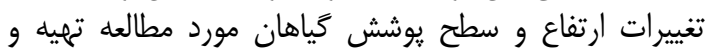
تفسير كرديدند. 


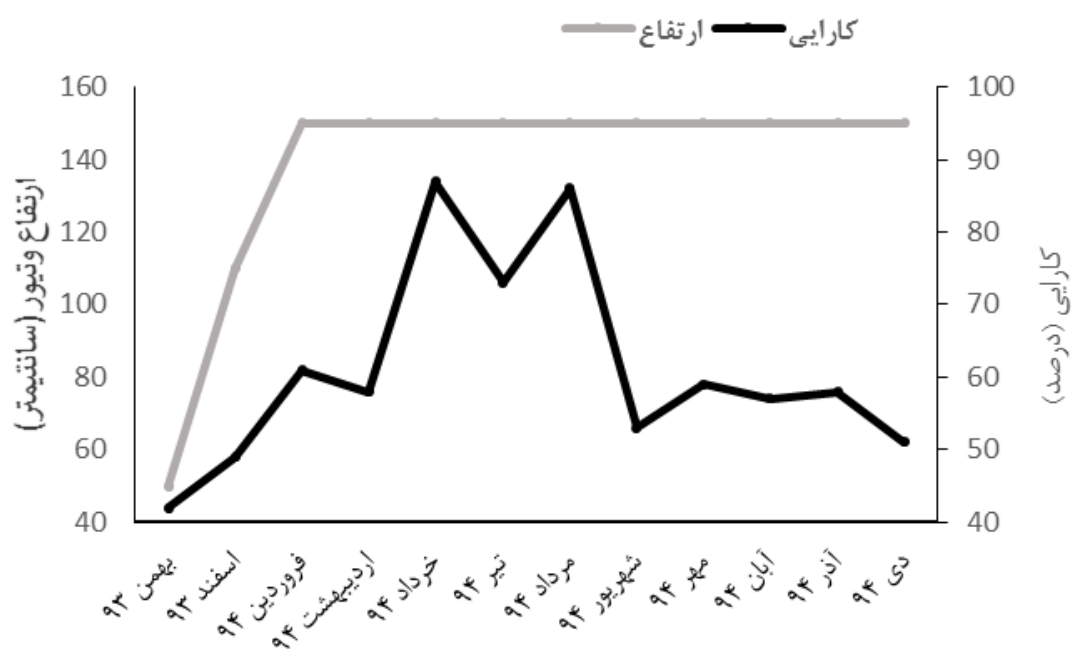

شكل V- تغييرات كارايى نوارهاى حائل كياهى حاوى وتيور و ارتفاع گَياه وتيور در طول دوره آزمايش

Figure 7. Variations of the efficiency of vetiver buffer strips and vetiver grass height during the study period

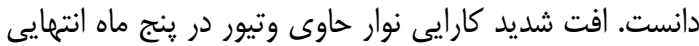

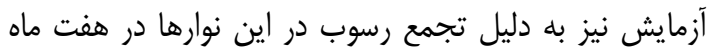

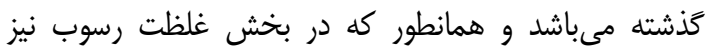

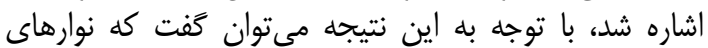

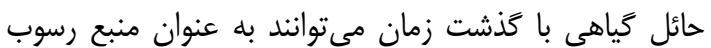
نيز ايفاى نقش نمايند.

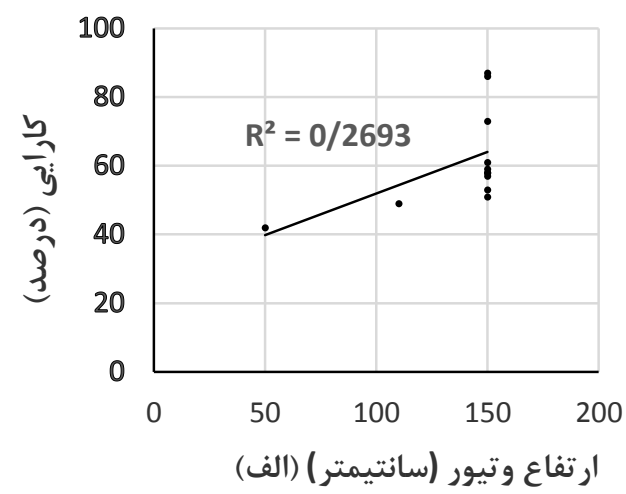

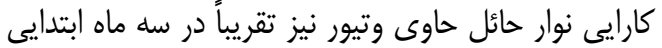

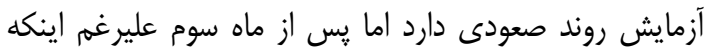

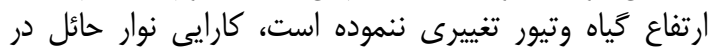

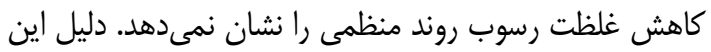

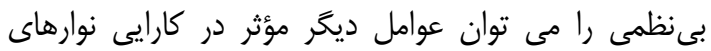

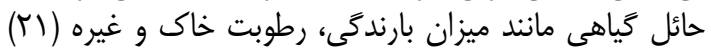

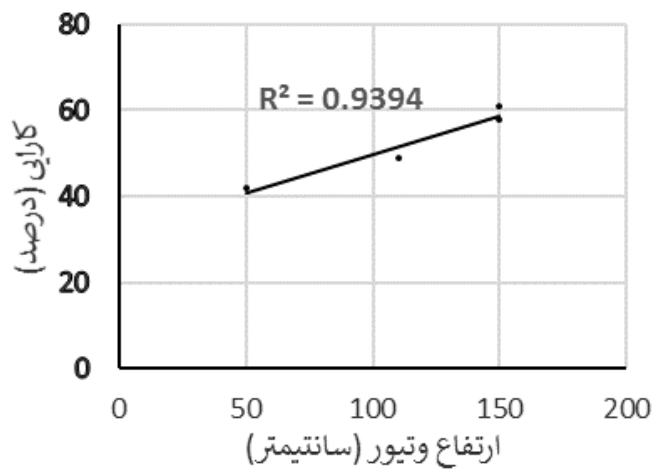

(ب)

شكل ^- الف) تغييرات كارايى نوارهاى حائل گياهى حاوى وتيور و ارتفاع گياه وتيور در طول دوره آزمايش ب) تغييرات كارايى نوارهاى حائل

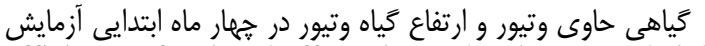

Figure 8. (a) Variations of the efficiency of vetiver buffer strips and vetiver grass height during the study period (b) Variations of the efficiency of vetiver buffer strips and vetiver grass height during the first four months of the study

كارايى نوارها و ارتفاع گياه وتيور نشان مى دهد (شكل ^) هرا

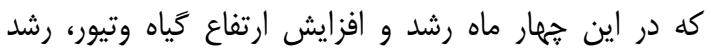

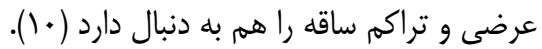

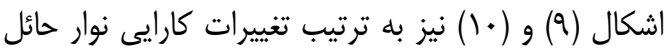

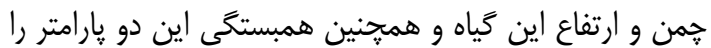

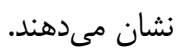

بررسى همبستخى بين كارايى نوارهاى حائل كياهى

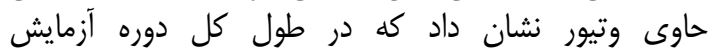

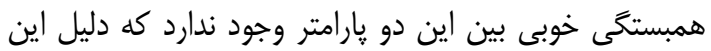

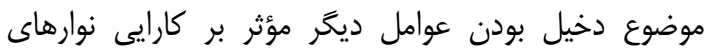

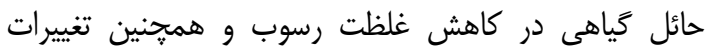

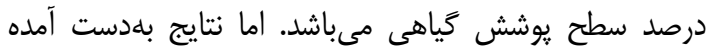

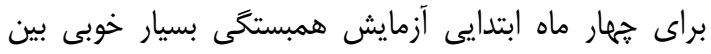




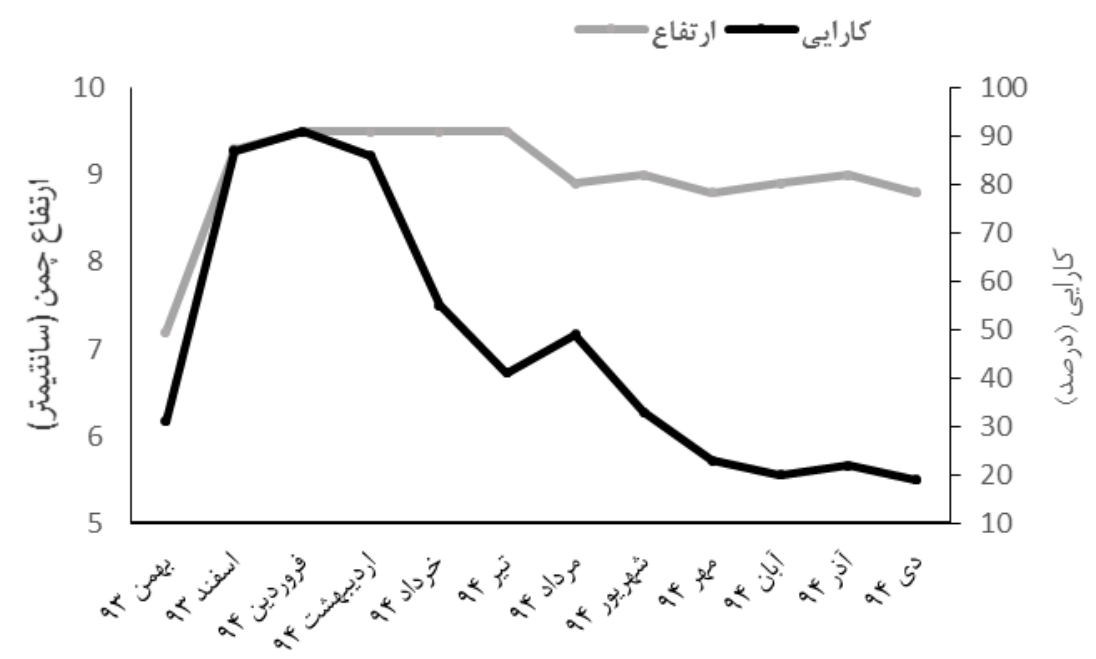

شكل q- تغييرات كارايى نوارهاى حائل كياهى حاوى جمن و ارتفاع گَياه جمن در طول دوره آزمايش

Figure 9. Variations of the efficiency of turf grass buffer strips and turf grass height during the study period
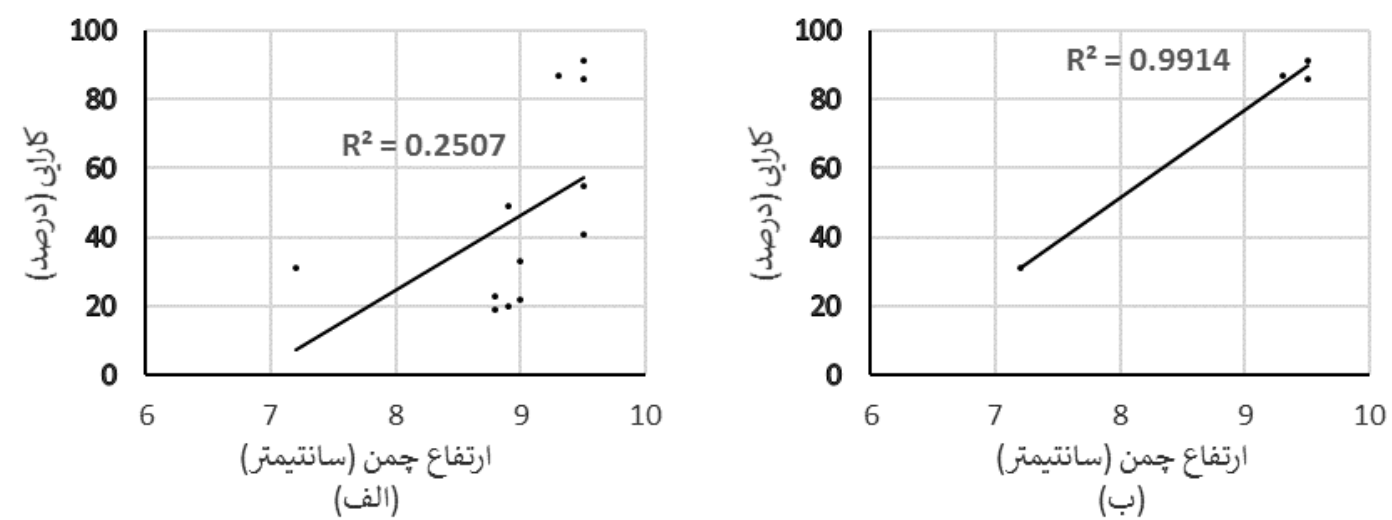

شكل • (- الف) تغييرات كارايى نوارهاى حائل كَاهى حاوى حمن و ارتفاع كَاه حمن در طول دوره آزمايش ب) تغييرات كارايى نوارهاى حائل

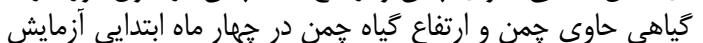

Figure 10. (a) Variations of the efficiency of turf grass buffer strips and turf grass height during the study period (b) Variations of the efficiency of turf grass buffer strips and turf grass height during the first four months of the study

افت شديدى گرديده و كارايى نوار حائل را تحت تأثير قرار داده است. سطح يوشش كياهى -كار اييى نوار حائل تياهى

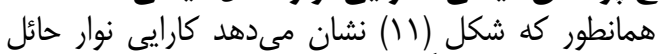

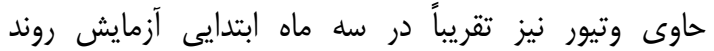

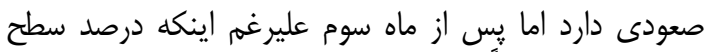

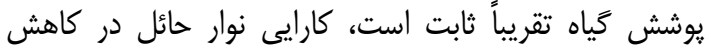

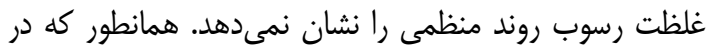

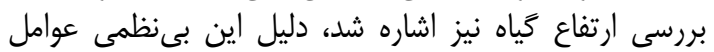

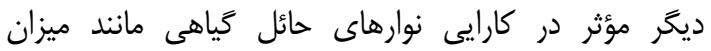

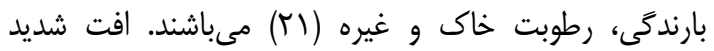

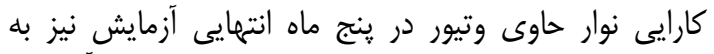

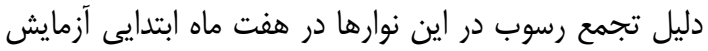

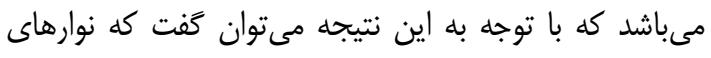

همانطور كه مشاهده مى شود، يِ از طائى روند صعودى

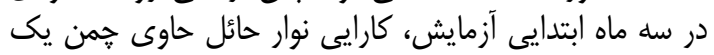

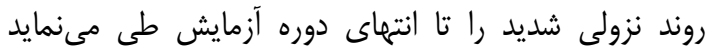

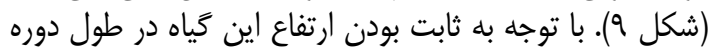

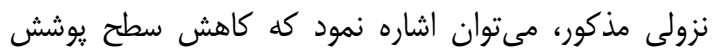

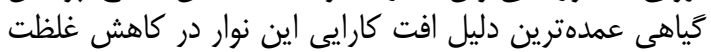

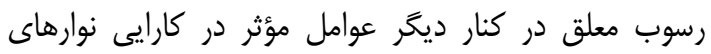

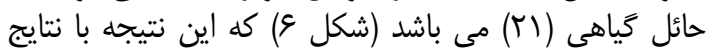

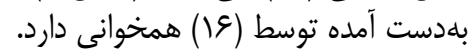

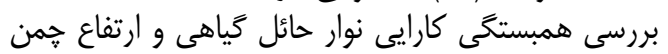

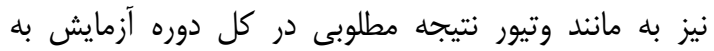

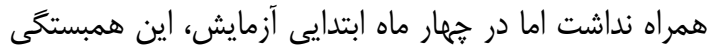

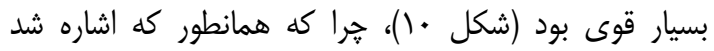

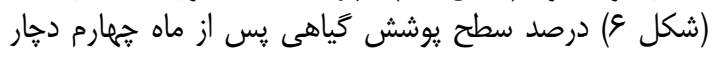


اوسبورن و كووإيج (·r)، باتاراى و همكاران (ا) و استاتر و

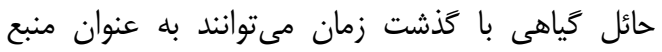

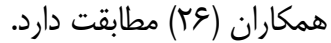

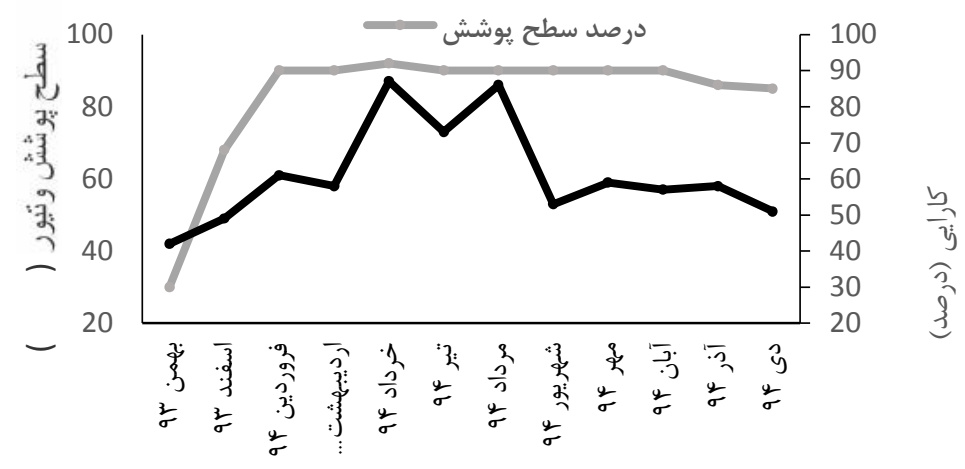

شكل I/- تغييرات كارايى نوارهاى حائل گياهى حاوى وتيور و درصد سطح يوشش گياهى وتيور در طول دوره آزمايش

Figure11. Variations of the efficiency of vetiver buffer strips and vetiver grass vegetation cover during the study period

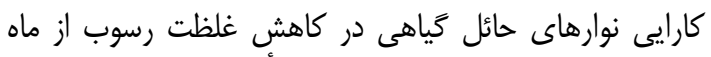

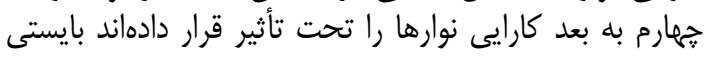

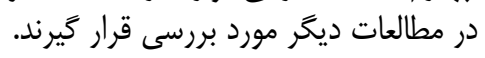

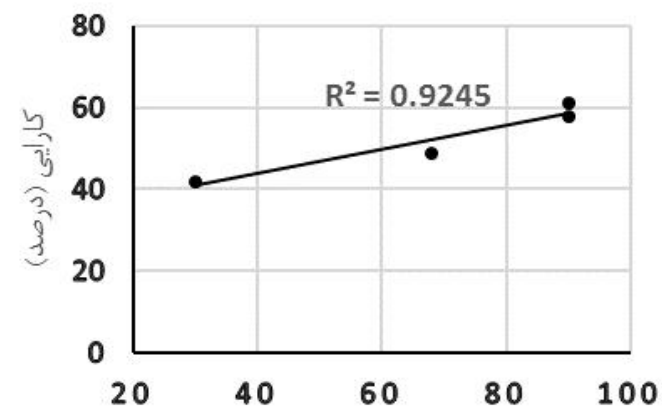

$$
\text { سطح يوشش وتيور (درصد) }
$$

(ب)
بررسى همبستخى بين كارايى نوارهاى حائل و سطح

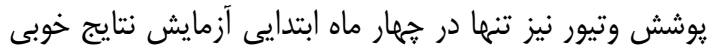

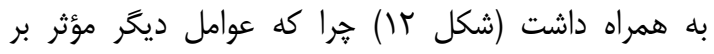

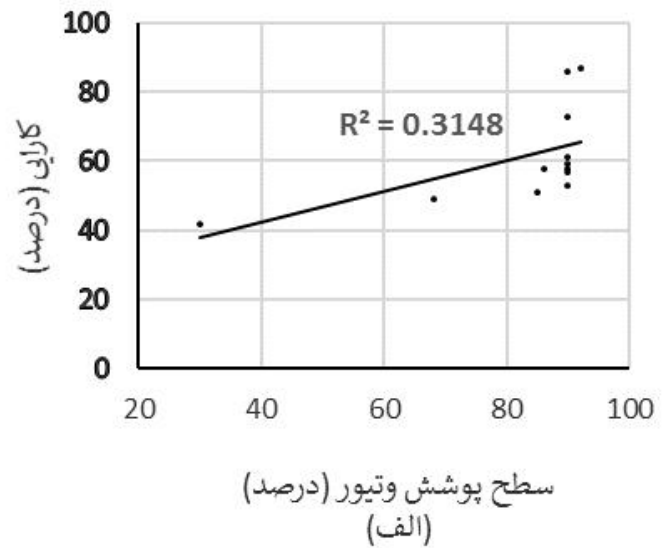

شكل rا - الف) تغييرات كارايى نوارهاى حائل كياهى حاوى وتيور و درصد سطح يوشش كياه وتيور در طول دوره آزمايش ب) تغييرات كارايى إيى

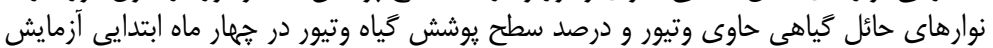

Figure 12. (a) Variations of the efficiency of vetiver buffer strips and vetiver grass vegetation cover during the study period (b) Variations of the efficiency of vetiver buffer strips and vegetation cover height during the first four months of the study

جمن نيز در طول دوره آزمايش كاهش يافت (شكل سار).

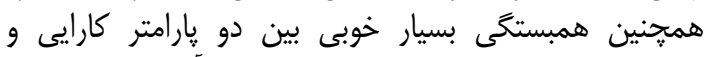

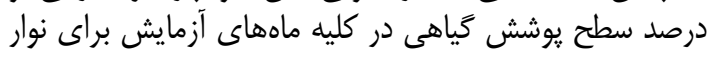
حائل حاوى جمن مشاهده كرديد (شكل دأل
بيشترين ارتباط و همبستخى در كل نتايج بلهدست آمده در

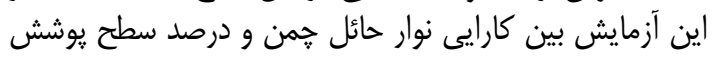

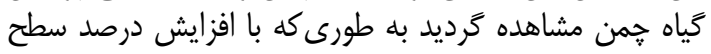

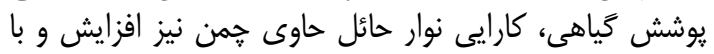

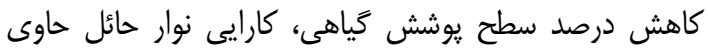




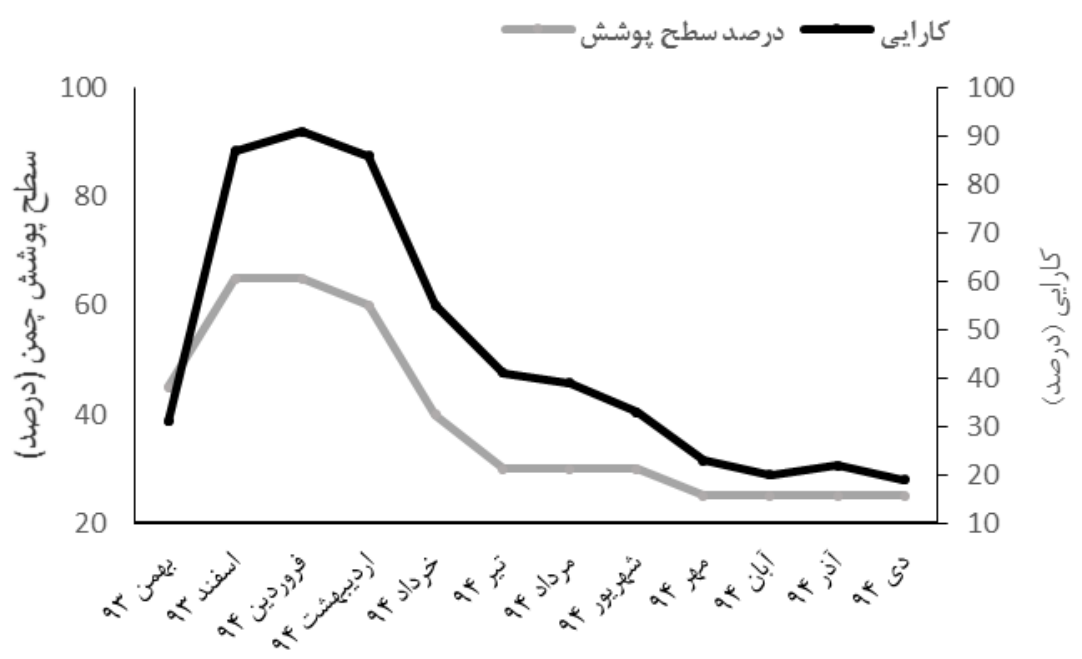

شكل با - تغييرات كارايى نوارهاى حائل كياهى حاوى جمن و درصد سطح يوشش كياهى جمن در طول دوره آزمايش

Figure13. Variations of the efficiency of turf grass buffer strips and turf grass vegetation cover during the study period

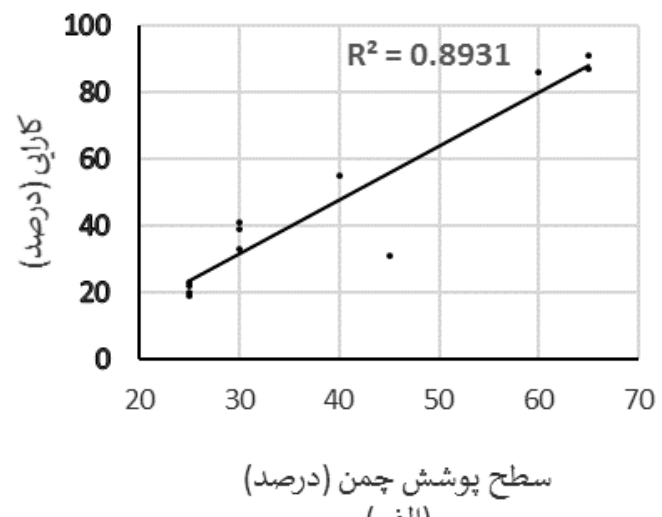

(الف) حرن)

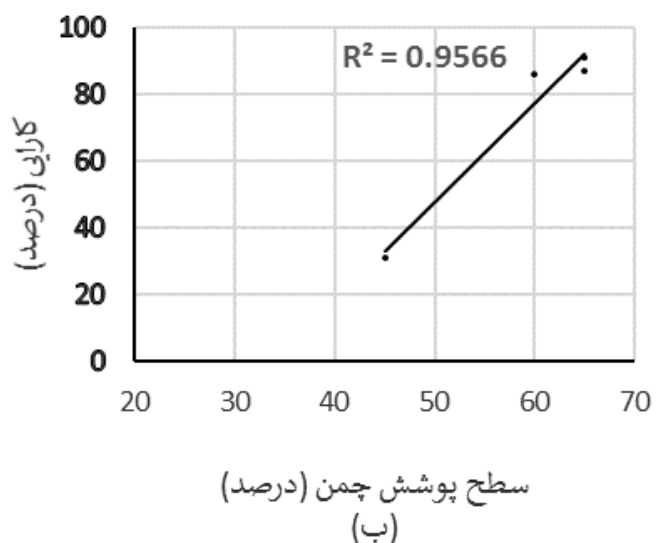

(ب)

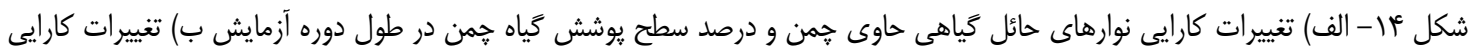

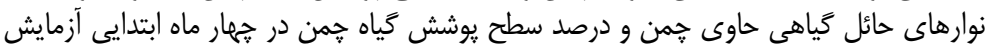

Figure14. (a) Variations of the efficiency of turf grass buffer strips and vegetation cover during the study period (b) Variations of the efficiency of turf grass buffer strips and vegetation cover during the first four months of the study

همانطور كه مشاهده شد ارتفاع و سطح يوشش كياه كهن

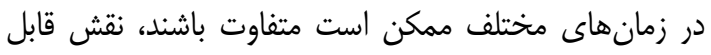

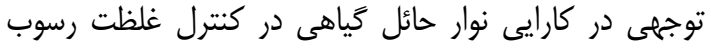

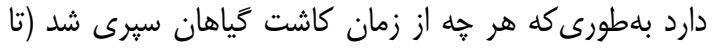

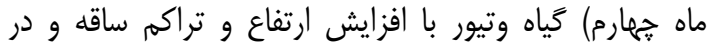
نتيجه درصد سطح يوشش خوداه

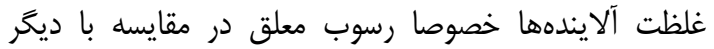

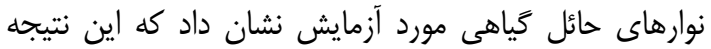

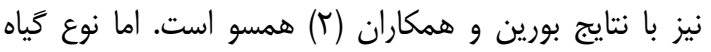

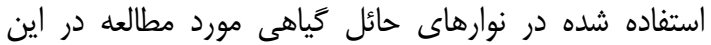

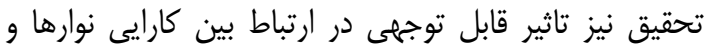

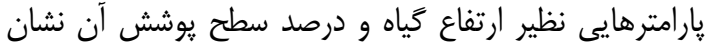

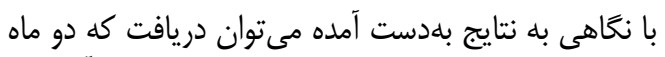
يس إز كاشت كياهان، نوارهاى حائل كياهى ماني مورد آزمايش

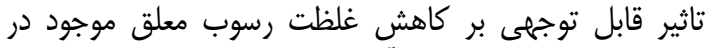

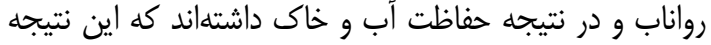

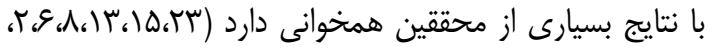

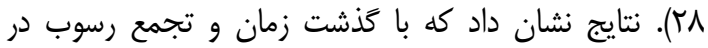

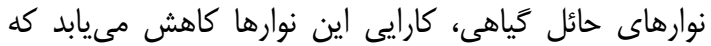

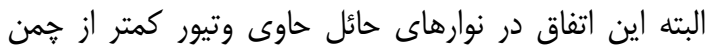

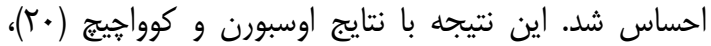

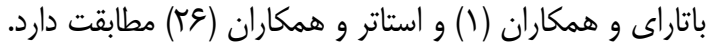

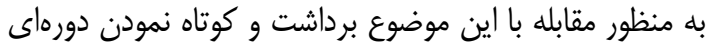

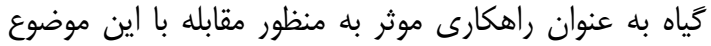
توصيه مى كردد. 


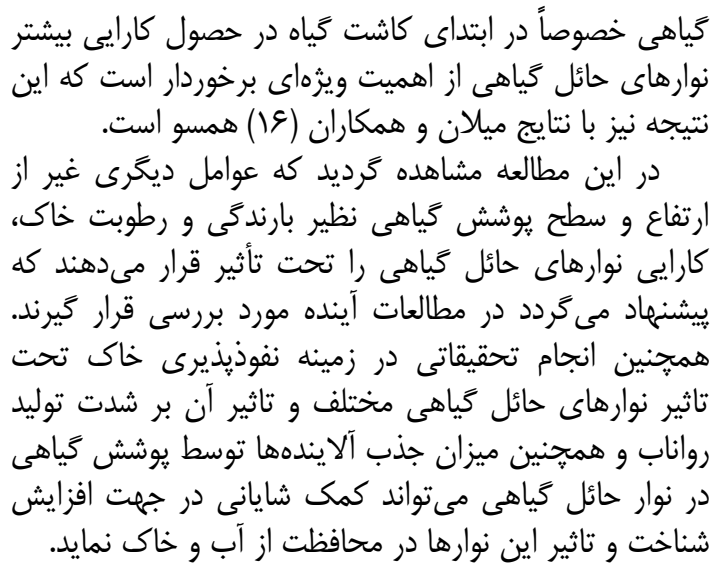

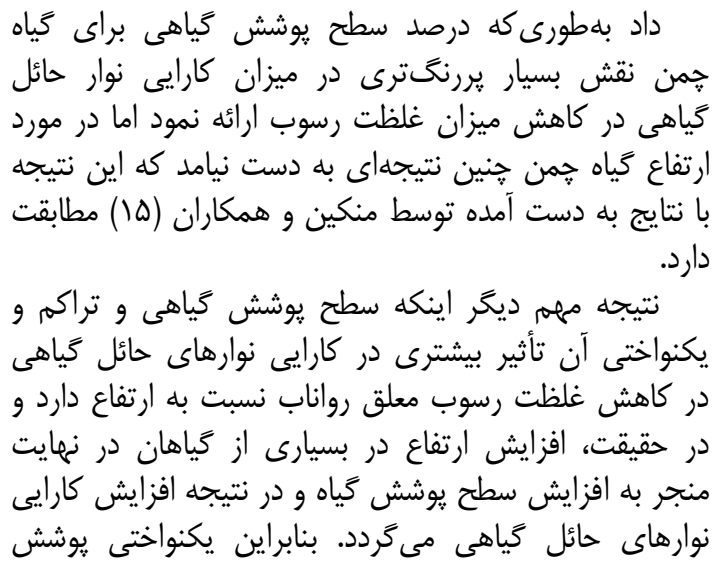

1. منابع subsurface drainage. Journal of Environmental Management, 90: 1868-1876.

2. Borin, M., M. Passoni, M. Thiene and T. Tempesta. 2010. Multiple functions of buffer strips in farming areas. Europ. J. Agronomy, 32: 103-111.

3. Borina, M., M. Vianelloa, F. Moraria and G. Zaninb. 2005. Effectiveness of buffer strips in removing pollutants in runoff from a cultivated field in North-East Italy. Agriculture, Ecosystems and Environment, 105: 101-114.

4. Dabney, S.M. 2003. Erosion control, vegetative. Encyclopaedia of Water Science. Marcel Dekker, Madison Ave, New York, USA.

5. Delgado, A.N., E.L. Periago and F.D. Viqueira. 1995. Vegetated filter strips for wastewater purification: a review. Bioresource Technology, 51: 13-22.

6. Duchemin, M. and R. Hogue. 2009. Reduction in agricultural non-point source pollution in the first year following establishment of an integrated grass/tree filter strip system in southern Quebec (Canada). Agriculture, Ecosystems and Environment, 131: 85-97.

7. Golabi, M.H., C. Iyekar, D. Minton, C.L. Raulerson and J.C. Drake. 2005. Watershed Management to Meet Water Quality Standards by Using the Vetiver System in Southern Guam. AU J.T., 9(1): 63-70.

8. Hay, V., W. Pittroff, E.E. Tooman and D. Meyer. 2006. Effectiveness of vegetative filter strips in attenuating nutrient and sediment runoff from irrigated pastures. Journal of Agricultural Science, 144: 349-360.

9. Hussein, J., B. Yu, H. Ghadiri and C. Rose. 2007. Prediction of surface flow hydrology and sediment retention upslope of a vetiver buffer strip. Journal of Hydrology, 338: 261-272.

10. Iranian association for vetiver promotion 2008. Vetiver system to prevent and treatment of chemical pollutions of water and soil (In Persian).

11. Kashi Zenouzi, L., H. Ahmadiand and A.A. Nazari Samani. 2015. Using Statistical Hydrogeomorphology Method for Estimating Sediment Yield of Watersheds (Case study: Zonouz Chay and Zilber Chay watersheds). Journal of Watershed Management Research, 6(12): 166-174. (In Persian)

12. Kelarestaghi, A.A., H. Ahmadi, A. Esmaeili Ori and J. Ghodusi. 2008. Comparison of runoff and sediment production in various agricultural landuse treatments. Iran-Watershed Management Science and Engineering, 2(5): 41-52 (In Persian).

13.Lambrechts, T., S. Francois, S. Lutts, R. Munoz-Carpena and C. Bielders. 2014. Impact of plant growth and morphology and of sediment concentration on sediment retention efficiency of vegetative filter strips: Flume experiments and VFSMOD modeling. Journal of Hydrology, 511: 800-810.

14. Lee, K.H., T.M. Isenhart, and R.C. Schultz. 2003. Sediment and nutrient removal in an established multi-species riparian buffer. Journal of Soil and Water Conservation, 58(1): 1-8.

15.Lee, K.H., T.M. Isenhart, R.C. Schultz and K.S. Mickelson. 1999. Nutrient and sediment removal by switchgrass and cool-season filter strips in Central Iowa, USA. Agroforestry Systems, 44: 121-132.

16. Mankin, K.R., M.N. Daniel, J.B. Charles, L.H. Stacy and A.G. Wayne. 2007. Grass-Shrub Riparian Buffer Removal of Sediment, Phosphorus, and Nitrogen from Simulated Runoff. Journal of the American Water Resources Association (JAWRA), 43(5): 1108-1116.

17. Milan, M., A. Ferrero, M. Letey, F. De Palo and F. Vidotto. 2014. Effect of buffer strips and soil texture on runoff losses of flufenacet and isoxaflutole from maize fields. Journal of Environmental Science and Health, Part B, 48: 1021-1033.

18. Mohammadi Golrang, B., Gh. Gazanchian, R. Ramzani Moghadam, H. Falahati, H. Rouhani and M. Mashayekhi. 2008. Estimation of forage yields of some range plant species by plant height and diameter measurements. Iranian journal of Range and Desert Reseach, 15(2): 158-178.

19. Morgan, R.P.C. 1995. Soil erosion and conservation, $2^{\text {nd }}$ edn. Longman, Addison.

20.Norris, V. 1993. The use of buffer zones to protect water quality: A review. Water Resources 
Management, 7: 257-272.

21. Osborne, L.L. and D.A. Kovacic. 1993. Riparian vegetated buffer strips in water-quality restoration and stream management. freshmler Biology, 29: 243-258.

22. Otto, S., A. Cardinali, E. Marotta, C. Paradisi and G. Zanin. 2012. Effect of vegetative filter strips on herbicide runoff under various types of rainfall. Chemosphere, 88: 113-119.

23.Pan, Ch. and Z. Shangguan. 2006. Runoff hydraulic characteristics and sediment generation in sloped grassplots under simulated rainfall conditions. Journal of Hydrology, 331: 178-185.

24.Patty, L., B. Real and J. Gril. 1997. The Use of Grassed Buffer Strips to Remove Pesticides, Nitrate and Soluble Phosphorus Compounds from Runoff Water. Pestic. Sci., 49: 243-251.

25.Ramezanipour, E., A. Mosaedi and M. Mesdaghi. 2017. Determination of the Best Model for Estimation of Suspended Sediment by using Statistical Error Criteria (Case study: Some SubWatersheds of Kashaf Roud). Journal of Watershed Management Research, 8(15): 166-174 (In Persian).

26. Sadeghi Ravesh, M. H. 2011. Comparison of human thermal comfort amount in arid and humid climates (Case study: Yazd and Sari cities). Arid Biom Scientific and Research Journal, 1(2): 50-61 (In Persian).

27. Shooshtarian, S. and A. Tehranifar. 2011. Introducing the vetiver grass. Journal of Iranian Agricultural Science, $170 \mathrm{pp}$.

28. Stutter, M., S. Langan and A. Lumsdon. 2009. Vegetated buffer strips can lead to increased release of phosphorus to waters: A biogeochemical assessment of the mechanisms. Environment Science Technology, 43: 1858-1863.

29. Verstraeten, G., J. Poesen, J.D. Vente and X. Koninckx. 2003. Sediment yield variability in Spain: a quantitative and semiqualitative analysis using reservoir sedimentation rates. Geomorphology, 50: 312- 327.

30.Wang, L., J. Duggin and D. Nie. 2012. Nitrateenitrogen reduction by established tree and pasture buffer strips associated with a cattle feedlot effluent disposal area near Armidale, NSW Australia. Journal of Environmental Management, 99: 1-9.

31. Yuan, Y., R.L. Bingner and M.A. Locke. 2009. A Review of effectiveness of vegetative buffers on sediment trapping in agricultural areas. Journal of Ecohydrology, 2: 321-336. 


\title{
Evaluating the Effects of height and Canopy of Vegetative Buffer Strips on Sediment Transport Reduction
}

\section{Iman Saleh ${ }^{1}$, Ataollah Kavian ${ }^{2}$, Mahmoud Habibnezhad Roshan ${ }^{3}$ and Zeinab Jafarian ${ }^{4}$}

1, 3 and 4- Graduated Ph.D. Student, Professor and Associate Professor, Faculty of Natural Resources, Sari Agricultural Sciences and Natural Resources University

2- Associate Professor, Faculty of Natural Resources, Sari Agricultural Sciences and Natural Resources University (Corresponding author: a.kavian@sanru.ac.ir)

Received: 30 August 2016

Accepted: 4 April 2017

\begin{abstract}
Soil erosion is one of the most serious environmental issues in the world. Vegetative buffer strips include a specific plant being passed by flow before entering the waterways, so it causes to reduce runoff volume, deposited pesticides and other pollutants of the flow through infiltration, absorption and sediment deposition. The present study has been carried out with aim to investigate the effect of plant height and canopy on the efficiency of vegetative buffer strips to reduce sediment transport. This study was conducted using $1 \times 10$ experimental plots and producing artificial runoff with a discharge rate as much as precipitation with 100-year return period as well as two plant species of vetiver grass and native turf grass during one year in Lalim region of Sari, Mazandaran, Iran. The results indicated that, plant height and canopy which may be different in various time periods, have a considerable role in the efficiency of vegetative buffer strips to control sediment concentration. Also, it was found that the efficiency of vegetative buffer strips to reduce suspended sediment concentration of runoff is more affected by canopy and uniformity of plant density than plant height. In fact, increasing height in most of plants ultimately would cause to increase canopy and consequently the efficiency of vegetative buffer strips. Finally, it was suggested to do more studies on the other factors such as precipitation and soil moisture affecting the efficiency of vegetative buffer strips in order to improve understanding and effectiveness of vegetative buffer strips in water and soil conservation.
\end{abstract}

Keywords: Artificial runoff, sediment concentration, soil erosion, Lalim, vegetative buffer strips 